\title{
JOGOS DE TABULEIRO NA SALA DE AULA: PROPOSTA DE ENSINO DA GEOGRAFIA FÍSICA PELA ADAPTAÇÃO DO MONOPOLY®
}

\author{
BOARD GAMES IN THE CLASSROOM: a proposal of teaching Physical

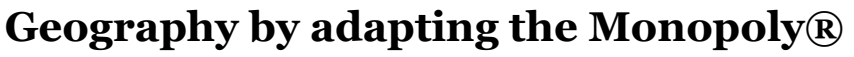

\author{
JUEGOS DE MESA EN AULA: una propuesta de enseñanza de la \\ Geografía Física adaptando el Monopolyß
}

Luiz Eduardo Panisset Travassos - luizepanisset@gmail.com
Professor do Departamento de Geografia da PUC Minas
Orcid : https://orcid.org/oooo-0001-6264-2429

Gleyber Eustáquio Calaça Silva - gleyber3001@gmail.com Doutorando em Geografia - Tratamento da Informação Espacial da PUC Minas Orcid : https://orcid.org/0000-0003-0318-7301

Gabriel Caldeira Gomes - profgabrielcaldeira@gmail.com Mestre em Geografia - Tratamento da Informação Espacial pela PUC Minas Orcid : https://orcid.org/0000-0003-3148-3685

Juliana Torres de Souza - julianatorres155@hotmail.com Graduada em Geografia - Licenciatura pela PUC Minas Orcid : https://orcid.org/000o-0003-2226-4683

\begin{abstract}
Resumo
A criatividade deve ser a norteadora para que alunos e professores desenvolvam o processo de ensino e aprendizagem da forma mais produtiva possível, sobretudo diante dos impactos oriundos da globalização e das novas tecnologias digitais que colocaram em xeque o modo tradicional de educação. Assim sendo, o presente trabalho tem por objetivo demonstrar como a adaptação de um jogo de tabuleiro para uso em sala de aula na Educação Superior pode favorecer a formação dos futuros professores de Geografia. Neste intuito, os autores e autora buscaram ajustar as regras existentes, bem como o tabuleiro e as cartas do jogo Monopolyß. Também foram elaborados arquivos para que o jogo pudesse ser utilizado e/ou adaptado para outras disciplinas e por qualquer um que se interesse pelo assunto. Os resultados apresentam a experiência didática da aplicação do jogo, que pode ficar ainda mais dinâmico com algumas alterações. O projeto e utilização deste recurso didático-pedagógico em sala de aula demonstrou ser eficiente e permitiu a interação entre os participantes durante as atividades de ensino e aprendizagem, sendo significativamente funcional no processo educativo.
\end{abstract}

Palavras-chave: Ensino, Geografia Física, Jogo de Tabuleiro.

\begin{abstract}
Creativity must guide students and teachers to develop the teaching and learning process in the most productive way possible, especially given the impacts arising from globalization and new digital technologies that have challenged the traditional way of education. Therefore, the present work aims to demonstrate how the adaptation of a board game for use in the classroom in Higher Education can favour the training of future Geography teachers. The authors sought to adjust the existing rules and the Monopoly $\AA$ game board and cards. Files were also created so that the game could be used and/or adapted to other disciplines and by anyone interested in the subject. The results show the didactic experience of applying the game, which can become even more dynamic with some changes. The design and use of this didacticpedagogical resource in the classroom proved to be efficient. Furthermore, they allowed interaction between participants during teaching and learning activities, being significantly functional in the educational process.
\end{abstract}


Keywords: Teaching, Physical Geography, Board games.

\section{Resumen}

La creatividad debe orientar a estudiantes y docentes a desarrollar el proceso de enseñanza y aprendizaje de la manera más productiva posible, especialmente dados los impactos derivados de la globalización y las nuevas tecnologías digitales que han desafiado la forma tradicional de educación. Por tanto, el presente trabajo tiene como objetivo demostrar cómo la adaptación de un juego de mesa para su uso en aula de Educación Superior puede favorecer la formación de futuros profesores de Geografía. Los autores buscaron ajustar las reglas existentes, el tablero y las tarjetas del juego Monopoly®. También se crearon archivos para que el juego pudiera ser utilizado y / o adaptado a otras disciplinas y por cualquier persona interesada en el tema. Los resultados muestran la experiencia didáctica de aplicar el juego, que puede volverse aún más dinámica con algunos cambios. El diseño y uso de este recurso didáctico-pedagógico en el aula resultó ser eficiente. Además, permitieron la interacción entre los participantes durante las actividades de enseñanza y aprendizaje, siendo significativamente funcionales en el proceso educativo.

Palabras clave: Docencia, Geografía Física, Juegos de mesa. 


\section{Introdução}

Muito se tem falado sobre as novas tecnologias e a sala de aula nos dias de hoje. O que se tem visto são trabalhos que exploram o uso do Google Earth, de aplicativos para smartphones ou vídeo games que são utilizados como recursos didáticos. Entretanto, é preciso lembrar que a tecnologia em sala de aula não deve ser restrita somente aquilo que pode ser alimentado por energia elétrica. Os quadros negros ou brancos também foram novas tecnologias implementadas em sala de aula para facilitar o processo de ensino e aprendizagem.

Por esse motivo, acredita-se que os jogos de tabuleiro são ferramentas apropriadas para a educação não formal, pois encorajam os alunos a participar de atividades em grupo, bem como administrar diferentes cenários que se apresentem durante o jogo. Entretanto, tais recursos ainda são muito subestimados, talvez pelo desconhecimento das muitas possibilidades envolvidas desde o seu processo de criação até seu uso em sala de aula.

Os jogos podem ser considerados oportunidades de aprendizagem que favorecem a interação entre os alunos e os professores, estimulando a cooperação, bem como a formação de conceitos, atuando no campo cognitivo dos envolvidos (CASTELLAR; VILHENA, 2010; SAWCZUK; MOURA, 2012). Pereira, Fusinato e Neves (2009) afirmam que são diversos os tipos de jogos que se encaixam na categoria de "tabuleiros" e os mais conhecidos do público em geral são a Dama, Trilha, Gamão, Xadrez, Banco Imobiliário, Monopoly, Jogo da Vida, Quest, Detetive, Scotland Yard e War.

Cada jogo possui características e benefícios de uso próprios, além de serem muito difundidos culturalmente. Outra vantagem está no fato de poderem ser jogados a qualquer hora e lugar, enquanto um jogo sem tabuleiro pode depender de condições que muitas vezes não são possíveis de controlar (e.g. tempo e lugar). Além disso, jogos de tabuleiro podem acomodar várias pessoas ao mesmo tempo. Quase todas as formas de entretenimento eletrônico são individualizadas e mesmo aqueles jogos de computador ou vídeo game (e.g. Xbox, PSP etc.) que apresentam a característica "multiplayer", forçam uma situação de cada um em seu lugar. Portanto, há pouco ou nenhum contato real entre as pessoas.

Os jogos de tabuleiro ou em grupo possibilitam aos indivíduos trabalharem com o limite, o respeito e a disciplina por meio de ações necessárias e subordinadas a regras, assim como se observa na vida em sociedade. O jogo é uma atividade rica e de grande efeito que responde às necessidades lúdicas, intelectuais e afetivas, estimulando a vida social e representando, assim, importante contribuição na aprendizagem. Uma das características mais importantes é a sua separação da vida cotidiana, constituindo-se em um espaço fechado com regras próprias definidas, mas mutáveis, onde os participantes atuam de forma descompromissada em uma espécie de "bolha lúdica", que, durante o jogo, não tem consequências no mundo exterior. No entanto, essa experiência enriquecedora é absorvida pelos participantes e pode refletir no mundo exterior de maneira muito positiva (SCHAEFFER, 2006; PEREIRA; FUSINATO; NEVES, 2009).

Sawczuk e Moura (2012) afirmam que por meio da resolução de problemas, os alunos desenvolverão o raciocínio lógico e social, ambos instrumentos valiosos para o ensino, pois despertam o interesse pelo conteúdo

TRAVASSOS, Luiz Eduardo Panisset; CALAÇA, Gleyber Eustáquio; GOMES, Gabriel Caldeira; DE SOUZA,

Juliana Torres. JOGOS DE TABULEIRO NA SALA DE AULA: proposta de ensino da Geografia Física pela adaptação do Monopoly®. Boletim Alfenense de Geografia. Alfenas. v. 1, n,1, p. 98-109, 2021.

https://doi.org/10.29327/243949.1.1-5 
trabalhado na disciplina. Por meio dos jogos, os autores afirmam que os alunos construirão e se apropriarão de conceitos fundamentais

Dessa forma, este trabalho explora a adaptação do jogo Monopolyß para uso em sala de aula na Educação Superior, especificamente para graduandos de licenciatura em Geografia. Para que o objetivo fosse atingido, os autores buscaram adaptar as regras existentes, bem como o tabuleiro e as cartas do jogo. Além disso, os autores elaboraram os arquivos para que o jogo possa ser utilizado e/ou adaptado para outras disciplinas e por qualquer um que se interesse pelo assunto.

\section{Procedimentos Metodológicos}

Além da revisão de literatura para constatar a importância de se usar jogos de tabuleiro no processo de ensino e aprendizagem, os autores se reuniram para traçar as etapas para elaboração do trabalho. Inicialmente, fez-se a escolha do jogo Monopoly® devido ao fato de sua "plataforma” permitir a adaptação para quase todas as temáticas possíveis. No mercado são encontrados diversos jogos da mesma marca com temáticas que vão desde museus (e.g. Museu do Louvre) a séries de televisão (e.g. Game of Thrones) e filmes como Guerra nas Estrelas, por exemplo (Figura 1).

\section{Figura 1 - Exemplos de três jogos temáticos do Monopoly®}

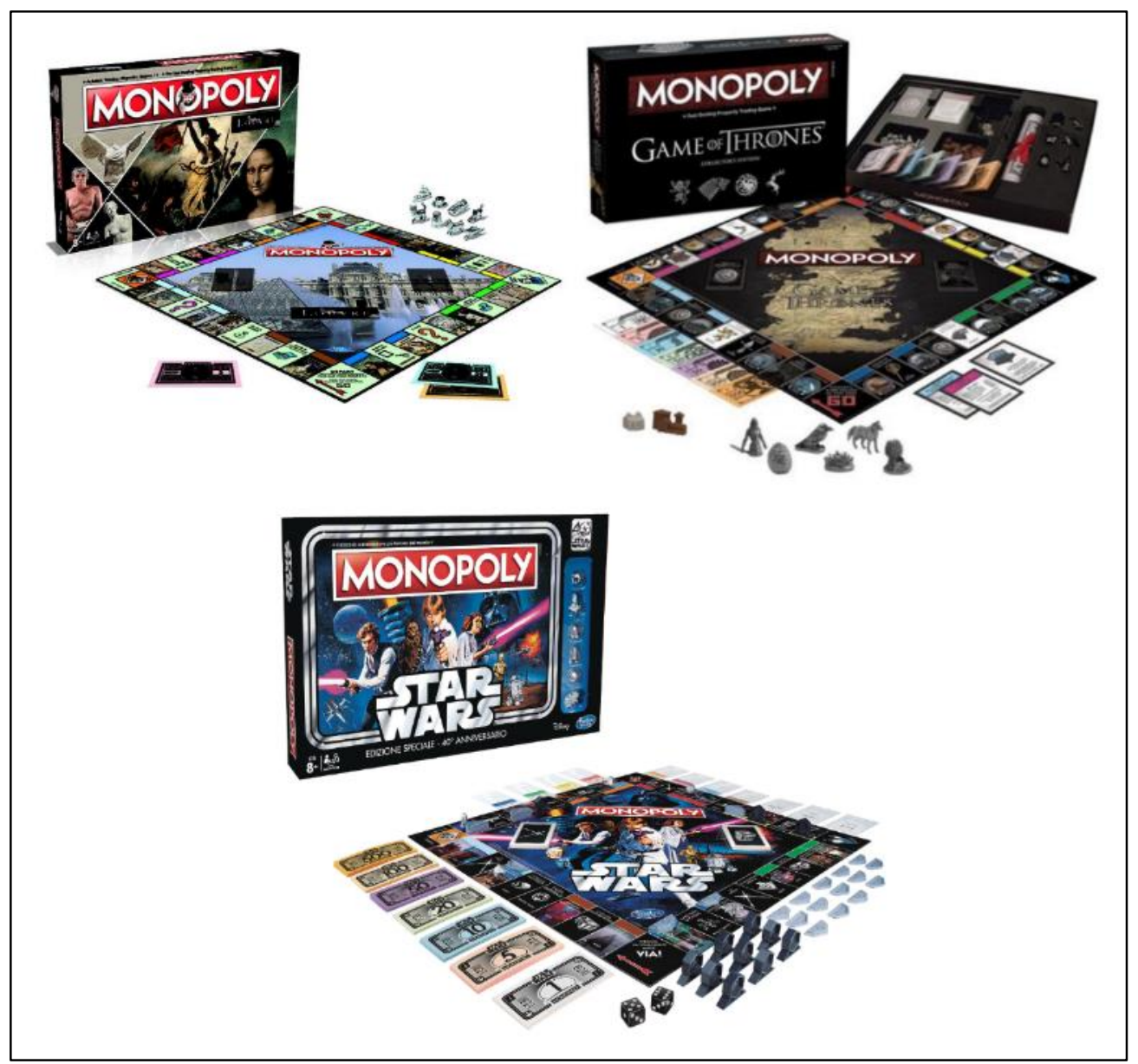

Fonte: https://monopoly.hasbro.com/worldwide

TRAVASSOS, Luiz Eduardo Panisset; CALAÇA, Gleyber Eustáquio; GOMES, Gabriel Caldeira; DE SOUZA, Juliana Torres. JOGOS DE TABULEIRO NA SALA DE AULA: proposta de ensino da Geografia Física pela adaptação do Monopoly®. Boletim Alfenense de Geografia. Alfenas. v. 1, n,1, p. 98-109, 2021. 
Feita a escolha pelo Monopoly®, optou-se pela criação de um tabuleiro que levasse em consideração os aspectos trabalhados na disciplina de Geomorfologia Climática e Estrutural do $5^{\circ}$ Período da Graduação em Geografia da PUC Minas. O layout (Figura 2) seguiu estritamente o proposto nos tabuleiros, desde a casa de início da partida em sentido horário até o retorno a esta casa. Os valores existentes no tabuleiro, bem como aqueles existentes nas "fichas de propriedades" e as "notas bancárias" também seguiram o proposto pelo jogo. A única diferença adotada foi a modificação entre os "hotéis" do jogo original para o que se convencionou chamar aqui de "melhorias" (Figura 3). Ao invés de "aluguel”, os jogadores são cobrados pela "visita” ao terreno adquirido (Figura 4).

\section{Figura 2 - Modelo de Tabuleiro proposto neste trabalho}

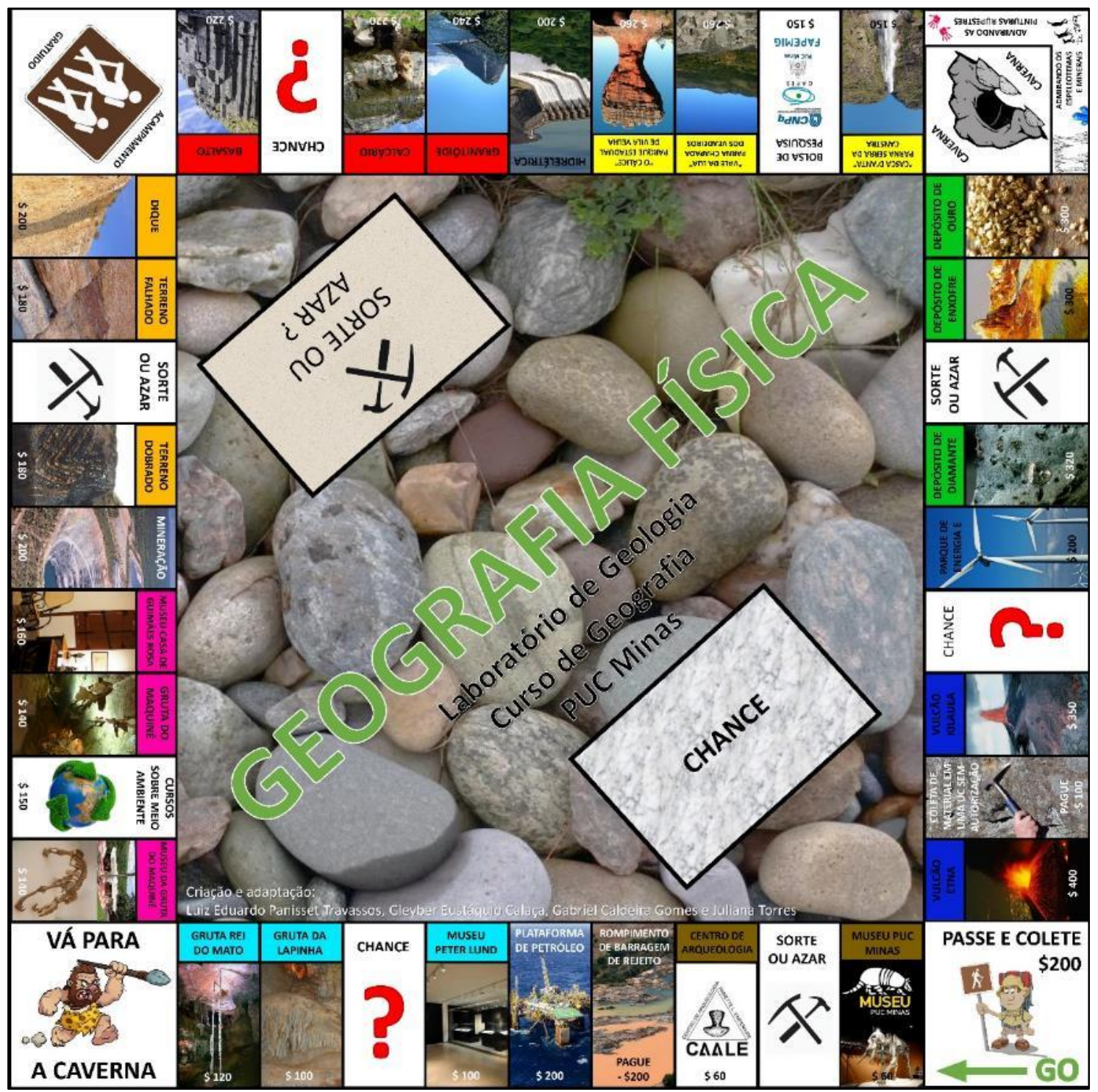

Elaborado pelos autores 
6). As "cédulas" utilizadas para negociar as propriedades também foram confeccionadas, conforme Figura 7.

Figura 5 - Detalhe das cartas "sorte ou azar"

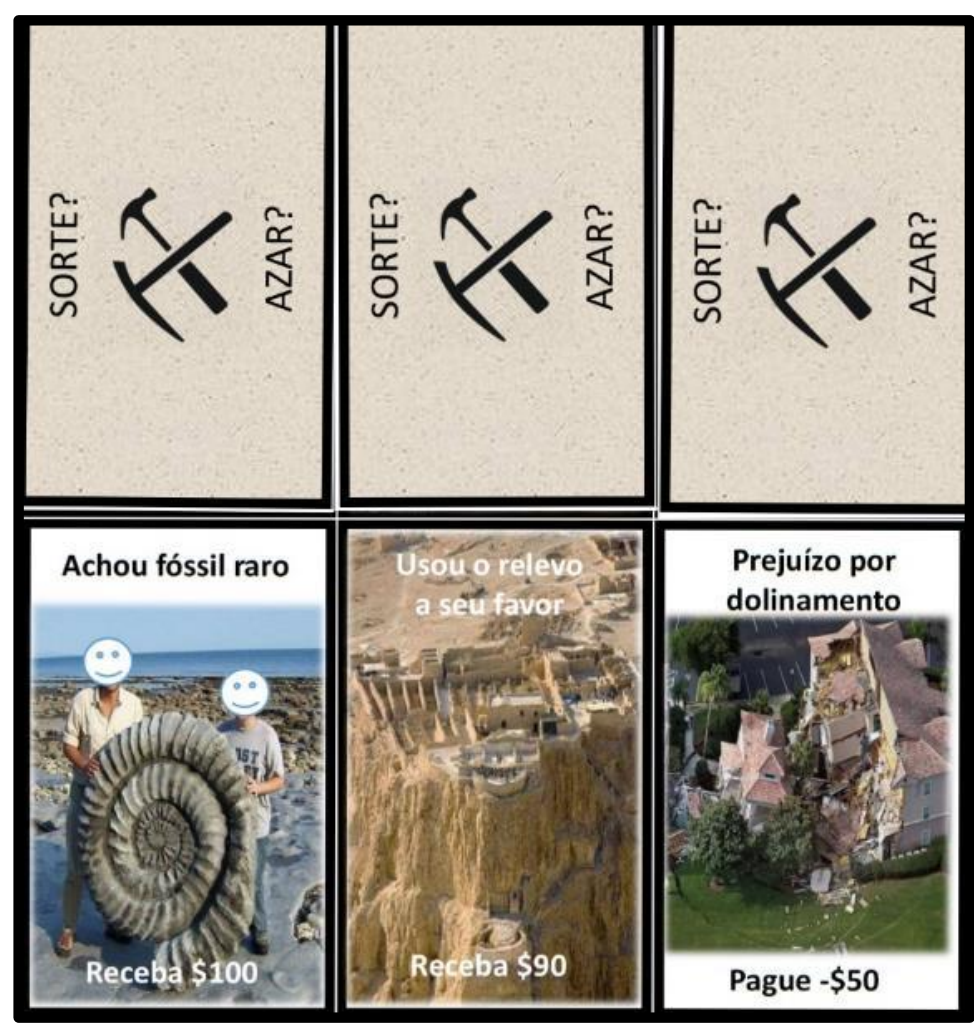

Adaptado pelos autores

Figura 6 - Peões do jogo de tabuleiro inspirados em grandes nomes das Ciências da Terra
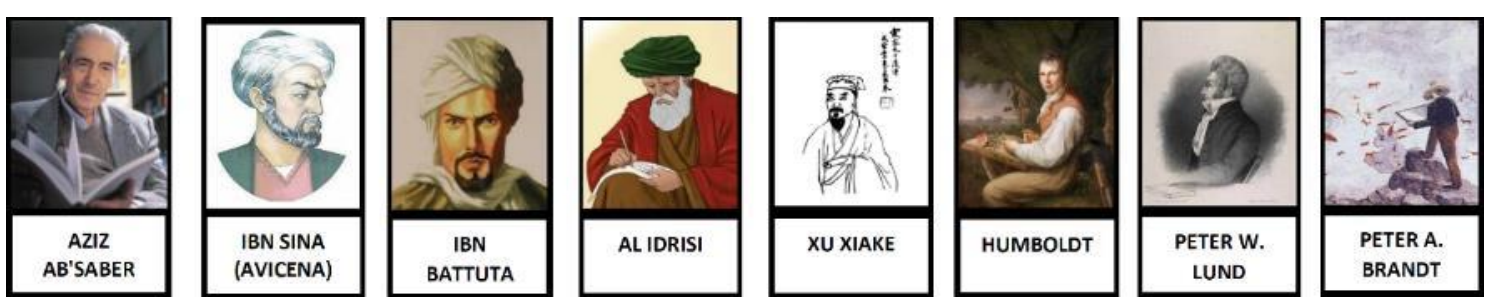

Adaptado pelos autores

Figura 7 - "Cédulas" fantasia do jogo de tabuleiro

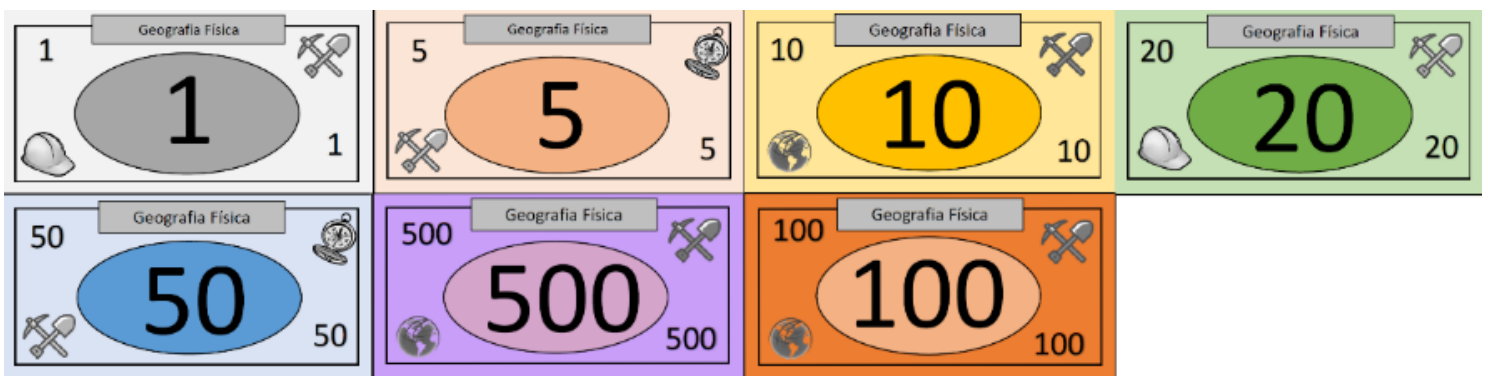

Adaptado pelos autores

TRAVASSOS, Luiz Eduardo Panisset; CALAÇA, Gleyber Eustáquio; GOMES, Gabriel Caldeira; DE SOUZA, Juliana Torres. JOGOS DE TABULEIRO NA SALA DE AULA: proposta de ensino da Geografia Física pela adaptação do Monopoly®. Boletim Alfenense de Geografia. Alfenas. v. 1, n,1, p. 98-109, 2021.

https://doi.org/10.29327/243949.1.1-5 


\section{Aplicando a Atividade: Instruções do Jogo}

Seguindo o padrão da maioria das versões do Monopoly®, os autores propuseram as seguintes instruções:

\section{Organização inicial:}

1. Escolha alguém para ser o responsável pela ordem (Orientador) e definam um tempo limite máximo para o jogo.

2. Monte o tabuleiro sobre uma superfície plana. Veja se todos os jogadores têm espaço suficiente para deixar o dinheiro e os títulos de propriedade na frente deles. As cartas de "Chance" e "Sorte e Azar" também devem ser colocadas no tabuleiro. O espaço para elas está marcado no tabuleiro.

3. Escolha uma peça. Cada jogador escolhe uma peça para movimentar pelo tabuleiro.

4. Dê $\$ 1500$ a cada jogador. Antes do jogo começar, orientador dá a cada jogador o dinheiro inicial deles. A soma total deve ser de $\$ 1500$, distribuídas da seguinte maneira:

2 notas de \$ 500;

2 notas de $\$ 100$;

2 notas de $\$ 50$;

6 notas de $\$ 20$;

5 notas de $\$ 10$;

5 notas de $\$ 5$;

5 notas de $\$ 1$.

Quem joga primeiro?

Quem tirar o número mais alto ao lançar os dados é o primeiro, e a rodada continua no sentido horário.

Jogando:

1. Jogue o dado e mova sua peça - Cada jogador lança os dados e move a peça pelo número de casas que tirou. Se tirar o mesmo número nos dois dados, você ganha uma jogada.

2. Olhe para o espaço onde você caiu - $\mathrm{O}$ jogo tem vários tipos diferentes de espaços. A maioria é de propriedades que você pode comprar ou pelas quais precisa pagar pela visita. No entanto, alguns exigem que você pague uma multa, receba dinheiro ou vá para a caverna.

3. Compre as propriedades quando cair nelas - Se cair em um espaço com uma faixa colorida na parte de cima, você pode comprar a propriedade pelo valor impresso no tabuleiro. O orientador, por sua vez, dá ao jogador a escritura de posse daquela propriedade. A maioria dos jogadores recomenda comprar toda a propriedade que você puder.

4. Receba pela visita - Se um jogador cair na propriedade de outra pessoa, ele precisa pagar ao proprietário o valor da visita que está impresso na carta de título da propriedade.

5. Compre todas as propriedades de uma mesma cor para obter um monopólio Se você se tornar dono de todas as propriedades de uma mesma cor, você tem um monopólio! Esse é um dos principais objetivos do jogo. 
6. Tenha melhorias nas suas propriedades - Se tiver todas da mesma cor, você pode começar a realizar melhorias nas propriedades para receber mais dinehiro. O preço de cada melhoria está no seu título de propriedade. É possível ter até quatro melhorias no seu terreno ou atrativo.

7. Ganhe \$200 quando passar pelo ponto de partida - Sempre que um jogador passar pelo ponto de partida, ele ganha \$200. Essa é uma ótima maneira de adicionar um dinheirinho às suas reservas!

8. Pegue uma carta de "Chance" ou "Sorte ou Azar" - Essas cartas podem fazer você perder ou ganhar dinheiro, ou ainda movê-lo para outro espaço. Se cair em um local com um ponto de interrogação ou martelos geológicos, pegue a carta superior da pilha correspondente. Quando terminar de ler a carta, devolva-a ao fundo da pilha. Nas "Chances", caso você acerte a pergunta, você receberá $\$ 35$.

9. Vá para a caverna - Ir para a caverna tira você do jogo até que esteja livre. Você não ganha pelas visitas de alguém nem compra propriedades ou faz negócios por uma rodada.

10. Hipoteque as propriedades - Se não conseguir pagar o valor das visitas ao cair em uma propriedade, você pode hipotecar suas propriedades. Quando uma propriedade é hipotecada, não é possível coletar o valor da visita. Para tirá-la da hipoteca, você precisa pagar 10\% de juros ao pagar a hipoteca.

\section{Resultados e Discussão}

Quase a totalidade dos artigos pesquisados para a revisão de literatura afirmam que, ainda hoje, os professores ainda encontram dificuldades em sala de aula, principalmente no que diz respeito a mobilizar os alunos para sua motivação à aprendizagem (SILVA; GOMES, 2012).

Moyles (2002) e Silva e Gomes (2012) afirmam que saber compartilhar é a principal condição para a construção do conhecimento e a reflexão é a principal condição para a construção do conhecimento. Portanto, é preciso refletir constantemente sobre as ações e estratégias do cotidiano escolar e, então, diversificar as metodologias de ensino. Para os autores, os jogos apresentam-se como uma boa alternativa, pois promovem situações de ensino-aprendizagem que aumentam a construção do conhecimento por serem atividades prazerosas, estimulam o interesse e a concentração.

A importância dos jogos na educação ocorre quando a diversão se torna aprendizagem, pois é muito mais eficiente aprender por meio de jogos, seja qual idade for. O jogo em si, possui componentes do cotidiano e o envolvimento desperta o interesse das pessoas fazendo-as serem sujeitos ativos do processo, inclusive, desde a sua confecção. O conhecimento é resultante das trocas, da interação entre sujeito e meio e, por isso, o jogo passa a ser uma ferramenta importante nos processos de desenvolvimento e aprendizagem (LOPES, 2001; SCHAEFFER, 2006; PEREIRA; FUSINATO; NEVES, 2009)

No entanto, conforme Custódio e Vieira (2015), não é desejável transformar os jogos no principal recurso em sala de aula, mas sim, mais um instrumento na intermediação do conhecimento entre os livros didáticos e a prática trabalhando o conteúdo de forma mais prazerosa a fim de garantir um outro tipo de motivação para o aprendizado. 
Desde o processo de criação até o jogo em si, percebeu-se o envolvimento dos graduandos envolvidos na elaboração das perguntas a serem utilizadas no jogo. Elaborar os diferentes elementos do jogo (e.g. tabuleiro, cartas e elementos adicionais) foram importantes para o trabalho em grupo, culminando em discussões sobre qual a melhor maneira de implementar e a resolução de possíveis problemas. Assim, para os alunos, o projeto do jogo é uma importante tarefa para a resolução de problemas que enfrentamos no dia a dia.

O fato dos jogadores comprarem e venderem propriedades, investindo em melhorias desenvolvem habilidades estratégicas. Ao andarem pelo tabuleiro, caindo nas casas das cartas de "Chance" e "Sorte ou Azar", os alunos têm a possibilidade de testar seus conhecimentos da disciplina, seja acertando ou não.

Inicialmente o jogo foi pensado para ter a seguinte configuração: 30 notas de 1,5,10,20,50,100 e 500; 20 cartas de "Chance"; 20 cartas de "Sorte ou Azar"; 28 propriedades; 40 melhorias; 8 peões e 2 dados. Com o teste do jogo em dois períodos diferentes, verificou-se a necessidade de aumentar a quantidade de notas, talvez dobrando a quantidade.

Em relação às cartas de chance (Figura 8), em ambos os testes, verificouse que os jogadores raramente caíram na casa destinada às perguntas. Por esse motivo, o jogo não apresentou o dinamismo idealizado inicialmente. Uma sugestão apresentada pelos próprios alunos jogadores foi a inclusão de mais perguntas. Assim, acertar seria o fator condicionante para se comprar ou não uma propriedade.

\section{Figura 8 - Exemplo das cartas "Chances", cujo gabarito somente é visível somente para o orientador que lê as perguntas}

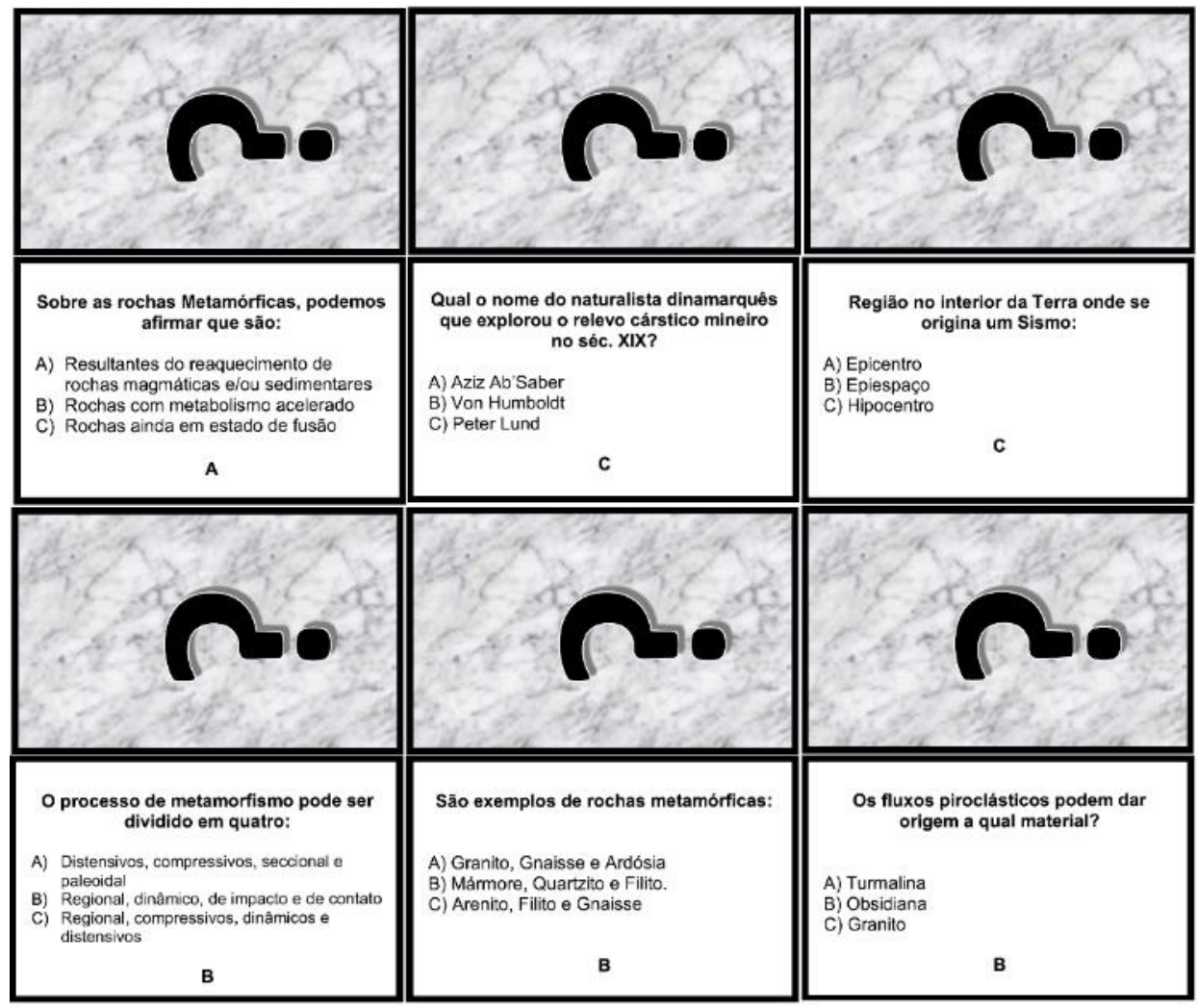

Adaptado pelos autores

TRAVASSOS, Luiz Eduardo Panisset; CALAÇA, Gleyber Eustáquio; GOMES, Gabriel Caldeira; DE SOUZA, Juliana Torres. JOGOS DE TABULEIRO NA SALA DE AULA: proposta de ensino da Geografia Física pela adaptação do Monopoly®. Boletim Alfenense de Geografia. Alfenas. v. 1, n,1, p. 98-109, 2021. 


\section{Considerações Finais}

O trabalho apresentou os jogos de tabuleiro como ferramenta pedagógica para auxiliar os alunos no estreitamento das relações sociais. A inclusão dos alunos no processo de concepção e construção do jogo é determinante para o sucesso.

A maior barreira em usar jogos em sala de aula pode ser a disponibilidade de recursos. Entretanto, a forma como os autores pensaram o trabalho levou em consideração os custos baixos de elaboração. Jogos bem elaborados criam uma atmosfera de engajamento além de favorecerem um ambiente que estimule os envolvidos a se concentrarem em áreas que precisam melhorar.

O jogo apresentado foi desenvolvido para ser um guia de educação informal que pode ser modificado para várias outras disciplinas agrupando uma grande variedade de tópicos. Adicionalmente, o conteúdo e o design podem ser modificados e adaptados de acordo com o nível do público a ser atingido.

Dessa forma, encoraja-se o uso e/ou adaptação do jogo apresentado que pode ser solicitado aos autores. Ao utilizar a proposta em sala será possível verificar os pontos positivos e negativos para melhorar o jogo para cada disciplina e nível educacional.

Como conclusão geral, o projeto e utilização do jogo em sala de aula é algo eficiente e permite a interação entre os participantes durante as atividades de ensino e aprendizagem, sendo significativamente funcional em à educação não formal.

\section{Referências}

CASTELLAR, S.; VILHENA, J. Ensino de Geografia. São Paulo: Cengage Learning, 2010.

CUSTÓDIO, A.F.; VIEIRA, J.N. Trilha Geográfica: uso de atividades lúdicas no ensino de Geografia. In: Encontro Nacional de Ensino de Geografia, 7, 2015.

Anais... Catalão (GO): AGB/UFG, 2015. Disponível em:

http://www.falaprofessor2015.agb.org.br/resources/anais/5/1441730502 ARQ

UIVO TRILHAGEOGRAFICA.pdf. Acesso em: 10 de fevereiro de 2019.

LOPES, M. da G. Jogos na Educação: criar, fazer e jogar. 4.ed. São Paulo: Cortez, 2001.

MOYLES, J.R. Só brincar? O papel do brincar na educação infantil. Porto Alegre: Artmed, 2002.

PEREIRA, R.F.; FUSINATO, P.A.; NEVES, M.C.D. Desenvolvendo um jogo de tabuleiro para o ensino de física. In: VII Encontro Nacional de Pesquisa em Educação Em Ciências, 7, 2009. Anais... Florianópolis, 2009. 
SAWCZUK, M. I. L.; MOURA, J. D. P. Jogos pedagógicos para o ensino da geografia. In: PARANÁ. Secretaria de Estado da Educação. Superintendência de Educação. O professor PDE e os desafios da escola pública

paranaense. Paraná: Secretaria de Estado da Educação, 2012. Disponível em: http://www.diaadiaeducacao.pr.gov.br/portals/cadernospde/pdebusca/produc oes pde/2012/2012 uel geo artigo marcia ines lorenzet sawczuk.pdf.

Acesso em: 04 de março de 2019.

SCHAEFFER, E. H. O jogo matemático como experiência de diálogo: análise fenomenológica da percepção de professores de matemática. Dissertação (Mestrado em Educação para a Ciência e o Ensino de Matemática).

Universidade Estadual de Maringá - PR, Maringá, 2006.

SILVA, J.P.; GOMES, M. de F.V.B. JOGOS PEDAGÓGICOS PARA O ESTUDO DAS FLORESTAS NO ENSINO DE GEOGRAFIA. In: PARANÁ. Secretaria de Estado da Educação. Superintendência de Educação. O professor PDE e os desafios da escola pública paranaense. Paraná: Secretaria de Estado da Educação, 2012. Disponível em:

http://www.diaadiaeducacao.pr.gov.br/portals/cadernospde/pdebusca/produc oes pde/2010/2010 unicentro geo artigo julsimar portela da silva.pdf. Acesso em: 04 de março de 2019. 